\title{
Rickettsia peacockii sp. nov., a New Species Infecting Wood Ticks, Dermacentor andersoni, in Western Montana $\dagger$
}

\author{
MARK L. NIEBYLSKI, ${ }^{*}$ MERRY E. SCHRUMPF, WILLY BURGDORFER, ELIZABETH R. FISCHER, \\ KENNETH L. GAGE, $\ddagger$ AND TOM G. SCHWAN \\ Laboratory of Microbial Structure and Function, Rocky Mountain Laboratories, National Institute of \\ Allergy and Infectious Diseases, National Institutes of Health, Hamilton, Montana 59840
}

\begin{abstract}
Rickettsia peacockii, a new species of spotted fever group rickettsiae, was identified from Rocky Mountain wood ticks (Dermacentor andersoni) collected in the Sapphire Mountain Range on the eastern side of Bitterroot Valley, Montana. DNA from $R$. peacockii Skalkaho ${ }^{\mathrm{T}}(\mathrm{T}=$ type strain) in naturally infected tick tissue was amplified by a PCR assay with primer sets derived from eubacterial 16S ribosomal DNA (rDNA), rickettsial citrate synthase, and 190-kDa surface antigen (rOmpA) genes. Partial 16S rDNA and rOmpA gene sequences exhibited levels of similarity of 99.7 and $93.2 \%$, respectively, with the sequences of the spotted fever agent Rickettsia rickettsii R. By using Giménez staining, fluorescent antibody tests, a PCR assay, and a restriction fragment length polymorphism analysis, 76 of 115 female ticks (minimal field infection rate, 66.1\%) collected between 1992 and 1995 were found to be infected. The organism is passed transstadially and transovarially (minimal vertical transmission rate, 73.3\%), and infections are localized in ovarial tissues. Attempts to cultivate $R$. peacockii were unsuccessful.
\end{abstract}

Rickettsiae are gram-negative bacteria that are maintained in nature by replication in cells of small mammals and arthropods $(5,7,23,32,47)$. At least 23 Rickettsia species (alpha subdivision of the Proteobacteria, family Rickettsiaceae) have been or are being described $(40,43)$, while undoubtedly more remain to be discovered. Of these species, Rickettsia rickettsii, the etiological agent of Rocky Mountain spotted fever (RMSF), is the most significant public health threat in the western hemisphere. Human RMSF cases were first recognized in 1873 in Bitterroot Valley in western Montana (34). Through a series of classic experiments begun in 1906, H. T. Ricketts and coworkers clearly established that the etiology of RMSF involves $R$. rickettsii in Rocky Mountain wood ticks (Dermacentor andersoni) (39). Transmission to humans occurs principally through bites of infected ticks. Between 1981 and 1992, 4,217 confirmed human RMSF cases (minimum case/fatality ratio, $4.0 \%$ ) were reported in the United States (9).

Since the pioneering work of Ricketts, several other species of rickettsiae have been recognized in Bitterroot Valley. A survey of 3,705 adult $D$. andersoni ticks collected in the valley during 1977 revealed four distinct serotypes of hemocyte-associated rickettsiae that were later identified as $R$. rickettsii, Rickettsia rhipicephali, Rickettsia montana, and Rickettsia bellii (33). Remarkably, only 2 of the 309 isolates found came from the 1,138 ticks collected on the eastern side of the valley, and both of these isolates were nonvirulent $R$. rhipicephali strains (33). With only one exception, spotted fever group (SFG) rickettsiae virulent for guinea pigs have never been recovered from east side wood ticks (32). These data correspond to the RMSF disease focality in the valley, where most human cases result

\footnotetext{
* Corresponding author. Mailing address: Rocky Mountain Laboratories, NIAID-NIH, 903 S. Fourth St., Hamilton, MT 59840. Phone: (406) 363-9376. Fax: (406) 363-9204. E-mail: mark_niebylski@nih.gov.

† This paper is dedicated to Mort G. Peacock in recognition of his lifelong contributions to rickettsiology, inimitable cell culture talents, and help provided to us and many others in studying rickettsiae.

$\ddagger$ Present address: Division of Zoonotic Diseases, Centers for Disease Control and Prevention, Ft. Collins, CO 80522.
}

from exposure to west side ticks $(8,32)$. In 1992, a PCR analysis of hemolymph samples from 226 west side $D$. andersoni adult ticks revealed that $4.0 \%$ of the samples were infected with one of three species of previously described rickettsiae (14). No dual rickettsial infections were reported in either the 1977 tick survey or the 1992 tick survey $(14,33)$.

Despite the low prevalence of hemocyte-associated rickettsiae in east side wood ticks, examination of the tissues of these ticks revealed that a high proportion are infected with rickettsiae. Parker and Spencer determined that $36 \%$ of wood ticks collected during 1925 from the eastern side of Bitterroot Valley harbored nonvirulent rickettsiae (29). In 1981, Burgdorfer et al. found that a nonvirulent rickettsia was transstadially and transovarially maintained in approximately $70 \%$ of the east side wood ticks examined but was uncommon in west side ticks (8). This organism was designated the east side (ES) agent. The ES agent has not been found in hemocytes, and, given the high natural infection rate, it seems likely that the ES agent went undetected in the 1977 and 1992 tick hemolymph surveys. Burgdorfer et al. postulated that the ES agent interfered with the stable maintenance of virulent rickettsiae in nature, thereby providing a plausible explanation for the focal distribution of RMSF in Bitterroot Valley (8). Unfortunately, the inability to cultivate the ES agent and distinguish it from other rickettsiae precluded further study at the time.

In this study, we identified the ES agent as a unique member of the genus Rickettsia which infects $D$. andersoni ticks. Staining, indirect fluorescent antibody (IFA) tests, and a PCR assay of tick tissues revealed that this organism is an apparent endosymbiont that can be distinguished from previously described rickettsiae. The results of DNA sequencing and a restriction fragment length polymorphism (RFLP) analysis, techniques which have been successful in helping to characterize rickettsiae and other bacteria associated with hematophagous arthropods $(1,3,10,14,20,38,41,46)$, indicated that the organism is a unique SFG rickettsial species. The sequence results suggest that strain Skalkaho ${ }^{\mathrm{T}}(\mathrm{T}=$ type strain) either lacks or has a truncated form of the major rickettsial $190-\mathrm{kDa}$ surface antigen (rOmpA). Unsuccessful attempts to cultivate the bacterium are also described below. 
TABLE 1. SFG rickettsial strains used to characterize $R$. peacockii Skalkaho ${ }^{T}$ and their GenBank nucleotide sequence accession numbers

\begin{tabular}{|c|c|c|}
\hline \multirow{2}{*}{ Strain } & \multicolumn{2}{|c|}{ Nucleotide sequence accession no. ${ }^{a}$} \\
\hline & rOmpA sequence & 16S rDNA sequence \\
\hline Rickettsia peacockii Skalkaho ${ }^{\mathrm{T} b}$ & $\mathrm{U} 55821^{c, d}$ & $\mathrm{U} 55820^{d, e}$ \\
\hline Rickettsia rickettsii $\mathrm{R}^{b}$ & U43804 & L36217 \\
\hline Rickettsia rickettsii $\mathrm{HLP}^{b f}$ & $\mathrm{U} 55823^{d}$ & $\mathrm{NA}^{g}$ \\
\hline Rickettsia conorii Malish $7^{b}$ & U01028 & U12460 \\
\hline Rickettsia japonica YM & U43795 & L36213 \\
\hline Rickettsia slovaca 13-B & U43808 & L36224 \\
\hline Rickettsia africae ESF-5 & U43790 & L36098 \\
\hline Rickettsia montana $\mathrm{M} / 5-6^{b}$ & $\mathrm{U} 55822^{d}$ & NA \\
\hline Rickettsia montana ATCC VR-611 & NA & U11016 \\
\hline Rickettsia rhipicephali 3-7-6 & U43803 & NA \\
\hline Rickettsia rhipicephali $85 \mathrm{TW}^{b}$ & NA & NA \\
\hline Rickettsia sibinica 246 & U43807 & NA \\
\hline Rickettsia parkeri Maculatum 20 & U43802 & NA \\
\hline Rickettsia massiliae GS & U43793 & NA \\
\hline $\mathrm{S}$ & U43805 & NA \\
\hline HA-91 & U43796 & NA \\
\hline BAR-29 & U43792 & NA \\
\hline MC16 & U43800 & NA \\
\hline WB8- $2^{b}$ & NA & NA \\
\hline $\mathrm{IXA}^{b}$ & NA & NA \\
\hline
\end{tabular}

${ }^{a}$ The sequences compared correspond to positions 91 through 602 and positions 29 through 1185 on the forward strand of the $R$. rickettsii $\mathrm{R}$ rOmpA and $16 \mathrm{~S}$ rDNA genes, respectively.

${ }^{b}$ SFG rickettsial strain used in RFLP analyses.

c The partial rOmpA gene sequences of $R$. peacockii generated from four infected ticks (laboratory colony tick RML-795 and field-collected ticks KG-392, SK-594, and SK-295) were identical and were represented by a single sequence submitted for Skalkaho ${ }^{\mathrm{T}}$.

${ }^{d}$ Sequence generated in this study (all other sequences were obtained from GenBank).

${ }^{e}$ The two 16S rDNA sequences of $R$. peacockii generated from two separate ticks (SK-594 and SK-295) were identical and were represented by a single sequence submitted for Skalkaho ${ }^{T}$

${ }^{f}$ Nonvirulent rickettsia isolated from Haemaphysalis ticks from the eastern side of Bitterroot Valley (28).

${ }^{g} \mathrm{NA}$, not applicable.

\section{MATERIALS AND METHODS}

Rickettsial strains. The rickettsial species described here was characterized directly from infected $D$. anderson $i$ tick ovarial tissues, and Skalkaho was designated the type strain (the strain designation refers to the local from which infected ticks were collected). For comparison, a number of SFG rickettsial strains were also employed in this study (Table 1); these strains included several organisms isolated from ticks in Montana $(4,30,33)$.

Ticks and screening of tick tissues for rickettsiae. Adult $D$. andersoni ticks were collected during May 1992, 1994, and 1995 by dragging a white flannel cloth (area, $1 \mathrm{~m}^{2}$ ) across vegetation where ticks were questing for hosts. All ticks were collected on Skalkaho Mountain in the Sapphire Mountain Range on the eastern side of Bitterroot Valley in Ravalli County, Mont. A laboratory colony naturally infected with Skalkaho ${ }^{T}$ was established from a tick (SK-594) collected in 1994. Both the laboratory colony and field-collected ticks were blood fed with guinea pigs as described previously $(18,21)$. Replete females were allowed to oviposit in $10-\mathrm{ml}$ glass tubes incubated at $27^{\circ} \mathrm{C}$ and $85 \%$ relative humidity, and the progeny were reared to adulthood (21).

Following oviposition, female ticks were surface sterilized by sequentially washing them for $10 \mathrm{~min}$ in hydrogen peroxide, $70 \%$ ethyl alcohol, and sterile distilled water $\left(\mathrm{dH}_{2} \mathrm{O}\right)$. Both field-collected and laboratory colony ticks were screened for rickettsial infections. First, ticks were tested for the presence of hemocyte-associated rickettsiae by the hemolymph test (6), and amputated legs were stored individually in $100 \mu \mathrm{l}$ of brain heart infusion (BHI) at $-20^{\circ} \mathrm{C}$ for a subsequent PCR assay. Next, tick salivary glands and ovarial tissues were removed with sterile forceps, washed three times in sterile $\mathrm{dH}_{2} \mathrm{O}$, and tested for the presence of rickettsiae. Malpighian tubules, midguts, and hypodermal tissues of a small proportion of the dissected ticks were also removed and screened for the presence of rickettsiae. Similarly, hemolymph, salivary glands, testicular tissues, Malpighian tubules, midguts, and hypodermal tissues from adult male ticks were also tested. Portions of individual tick tissues were either smeared on slides and fixed for staining and the IFA test or stored in $200 \mu \mathrm{l}$ of $\mathrm{BHI}$ at $-20^{\circ} \mathrm{C}$ for the PCR assay.
Individual heat-fixed smears of tissue samples were stained by the Giménez method (15) and were microscopically examined under oil immersion (magnification, $\times 1,000)$ for rickettsiae. In the IFA test performed to confirm rickettsia infections, smears of each acetone-fixed tissue sample were stained with anti- $R$ rickettsii guinea pig serum and then with fluorescein isothiocyanate-labeled mouse anti-guinea pig serum (31). A second IFA test was selectively performed on infected ovarial tissues from field-collected ticks (SK-594 and SK-295) and laboratory colony ticks (RML-295 and RML-795) which were used to obtain sequence data for the bacterium. In this IFA test, acetone-fixed tissue smears were stained separately with monoclonal antibody (MAb) 13-2 to rOmpB and MAbs 14-13 and 13-5 to rOmpA as described previously (2). Samples were then stained with fluorescein isothiocyanate-labeled rabbit anti-mouse serum. Each conjugate was diluted $1: 50$ in sterile $\mathrm{dH}_{2} \mathrm{O}$, incubated for $30 \mathrm{~min}$ at $27^{\circ} \mathrm{C}$, and then washed three times in phosphate-buffered saline. Cell-cultured $R$. rickettsi $R$ and rickettsia-free tick ovarial tissue were included in IFA tests as positive and negative controls, respectively. For comparison, $R$. rickettsii $\mathrm{R}$ and five other rickettsial strains were stained with MAbs. IFA slide preparations were examined with a fluorescence microscope under oil immersion (magnification, $\times 1,000$ ) for evidence of rickettsiae.

Morphological studies. Tick ovarial tissues from infected (RML-295 and RML-795) and uninfected (RML-195) females were examined for rickettsiae with a transmission electron microscope (model CM-10; Phillips) (24). The tissues were fixed overnight in $4 \%$ paraformaldehyde- $2.5 \%$ glutaraldehyde in $100 \mathrm{mM}$ sodium cacodylate buffer ( $\mathrm{pH} 7.4$ ). Cells were postfixed in $0.5 \%$ osmium tetroxide $-0.8 \%$ potassium ferricyanide and then in $1 \%$ aqueous tannic acid and stained overnight en bloc in $1 \%$ aqueous uranyl acetate. Samples were dehydrated through a graded ethanol series and embedded in Spurr's resin. Thin sections were cut with an ultramicrotome (model RMC MT-7000), stained with $1 \%$ aqueous uranyl acetate and Reynold's lead citrate, and observed at $80 \mathrm{kV}$.

Isolation and cultivation attempts. Tick ovarial tissues (five samples) infected with Skalkaho ${ }^{\mathrm{T}}$ were triturated with glass grinders in $5 \mathrm{ml}$ of $4 \%$ sucrose phosphate-glutamate buffer. Next, $0.25 \mathrm{ml}$ of the resulting suspension was inoculated intraperitoneally into six male meadow voles (Microtus pennsylvanicus) and six male Swiss mice (Mus musculus). Blood, liver, spleen, kidney, and tunica vaginalis tissue samples were removed on day 5 postinoculation. Blood clots and tissues were first screened for rickettsial infection by performing an IFA test. Samples were then triturated separately in $5 \mathrm{ml}$ of sucrose-phosphate-glutamate buffer, and $0.25 \mathrm{ml}$ of each suspension was inoculated onto Vero, $M$. pennsylvanicus tunica vaginalis (MTV), and Potorous tridactylus marsupial kidney epithelial (PTK2) cell monolayers. In parallel, infected tick ovarial tissues (nine samples) were triturated in $4 \mathrm{ml}$ of $\mathrm{BHI}$, and $0.2 \mathrm{ml}$ of each suspension and two 10 -fold serial dilutions were inoculated directly onto cell monolayers (28). The cell lines inoculated were Vero, MTV, PTK2, D. albipictus tick embryo, primary chicken embryo (PCE), mouse connective fibroblast, and mouse histiocytoma cell lines. Cultivation in chicken embryos was attempted previously without success (8). We attempted to establish a primary cell line from tick ovarial tissues by using standard methods (50).

Cells were cultivated in closed $75-\mathrm{cm}^{2}$ flasks (Corning, Inc, Corning, N.Y.) that were incubated at $34^{\circ} \mathrm{C}$ and contained $40 \mathrm{ml}$ of M199 medium (Gibco, Grand Island, N.Y.) supplemented with $2 \%$ fetal bovine serum and $10 \mathrm{mM}$ $\mathrm{L}$-glutamine. Tick cell cultures were grown in a special medium (25). Inoculated MTV and tick cells were also grown at $27^{\circ} \mathrm{C}$. In addition, separate flasks containing inoculated Vero, MTV, and PTK2 cells were supplemented with $0.005 \%$ dextran sulfate, $0.01 \%$ hemin, and $0.025 \%$ ferric pyrophosphate (Sigma Chemical Co., St. Louis, Mo.). All cell cultures were inoculated with mammalian or ovarial tissue samples in duplicate. One flask of each cell culture type was randomly screened for the presence of rickettsiae by Giménez staining and IFA test on days 4 through 20 postinoculation. Cells in the second flask were harvested on day 10 postinoculation and passaged into Vero and MTV cells (28). A maximum of four sequential passages were performed.

A modification of the centrifugation-shell vial technique was also employed in attempts to isolate and cultivate the organism (19). Briefly, infected ovarial tissue triturates were inoculated in triplicate into shell vials containing Vero, MTV, and PCE cell monolayers on M199 medium containing $2 \%$ fetal bovine serum and 10 $\mathrm{mM}$ L-glutamine. The shell vials were screened for the presence of rickettsiae on days 4 and 7 postinoculation. If one shell vial was found to be infected with rickettsia-like organisms, cells from a duplicate vial were passaged in new shell vials.

Attempts to plaque purify the organism were performed by using standard methods (49). Vero cells grown in six-well trays (Corning) with agar overlays were inoculated with serial dilutions of infected ovarial tissue (two samples) suspended in $1 \mathrm{ml}$ of BHI. These cells were observed daily for 2 weeks for evidence of plaque formation.

PCR assay. Tick reproductive tissues, salivary glands, amputated legs, midguts, Malpighian tubules, hypodermal tissues, and inoculated cell cultures were tested for rickettsial infection by a PCR assay. For this assay we used a rickettsial citrate synthase (CS) gene primer set (primers RpCS.877 and RpCS.1258n) and an SFG rOmpA gene primer set (primers $\operatorname{Rr} 190.70$ and $\operatorname{Rr} 190.602 \mathrm{n}$ ), as described previously (38). The rickettsial CS gene primer set amplified a 382-bp fragment corresponding to positions 877 through 1258 of the Rickettsia prowazekii CS gene. The rOmpA gene primer set amplified an approximately 533-bp fragment corresponding to positions 70 through 602 on the forward strand of the $R$. rickettsii 
TABLE 2. Summary of $R$. peacockii infections in tissues from field-collected and laboratory colony $D$. andersoni ticks as determined by Giménez staining, IFA tests, and PCR assays ${ }^{a}$

\begin{tabular}{|c|c|c|c|c|c|c|c|}
\hline \multirow{2}{*}{ Ticks } & \multirow{2}{*}{ Sex } & \multicolumn{6}{|c|}{ No. of samples positive for rickettsiae (no. tested) } \\
\hline & & Hemolymph & Salivary glands & Reproductive tissue ${ }^{b}$ & Malpighian tubules & Midguts & Hypodermal tissues \\
\hline \multirow[t]{2}{*}{ Field collected } & Female & 0/NT/0 $(115)^{c}$ & $0 / 0 / 0(115)$ & 76/76/81 (115) & $1 / 1 / 0(16)$ & $1 / 1 / 0(16)$ & $0 / 0 / 0(16)$ \\
\hline & Male & $0 / \mathrm{NT} / 0(36)$ & $0 / 0 / 0(36)$ & $0 / 0 / 0(36)$ & $0 / 0 / 0(36)$ & $0 / 0 / 0(36)$ & $0 / 0 / 0(36)$ \\
\hline \multirow[t]{2}{*}{ Laboratory colony } & Female & $0 / \mathrm{NT} / 0(45)$ & $0 / 0 / 0(45)$ & $33 / 33 / 34(45)$ & $1 / 1 / 0(10)$ & $1 / 1 / 0(10)$ & $0 / 0 / 0(10)$ \\
\hline & Male & $0 / \mathrm{NT} / \mathrm{NT}(65)$ & $0 / 0 / \mathrm{NT}(65)$ & $0 / 0 / \mathrm{NT}(65)$ & $0 / 0 / \mathrm{NT}(65)$ & $0 / 0 / \mathrm{NT}(65)$ & $0 / 0 / N T(65)$ \\
\hline
\end{tabular}

\footnotetext{
${ }^{a}$ In the IFA tests a polyclonal antibody to $R$. rickettsii $\mathrm{R}$ was used, and in the PCR assays both rickettsial CS and rOmpA gene primer sets were used.

${ }^{b}$ Five ovarial tissue samples that were negative for rickettsiae as determined by Giménez staining and IFA tests were positive as determined by PCR assays. The organisms in these samples and 35 other samples were identified as $R$. peacockii by an RFLP analysis. All tissues that were positive for rickettsiae gave amplification products with both primer sets.

Number of positive samples as determined by Giménez staining/number of positive samples as determined by IFA tests/number of positive samples as determined
} by PCR assays (number of samples tested). NT, not tested.

rOmpA gene. These primer sets have been useful for detecting and identifying rickettsiae in arthropods $(3,37,48)$, including wood ticks $(12,14)$.

A PCR assay, in which a eubacterial $16 \mathrm{~S}$ ribosomal DNA (rDNA) conserved gene primer set (27) was used, was then conducted with tick ovarial tissues which had already tested positive for rickettsial infection as determined by Giménez staining, two separate IFA tests, and PCRs performed with both the rickettsia CS gene and rOmpA gene primer sets. The $16 \mathrm{~S}$ rDNA gene primer set $\left(5^{\prime}-\mathrm{GC}\right.$ TTAACACATGCAAG [Escherichia coli positions 45 to 61 ] and $5^{\prime}$-CCATTG' AGCACGCGT [ $E$. coli positions 1242 to 1227 reverse]) was modified for use in our study by switching a single base on the forward primer. This primer set amplifies an 1,157-bp fragment which corresponds to positions 29 through 1185 on the forward strand of the $R$. rickettsii 16S rDNA gene.

Prior to the PCR assay, individual tick tissue samples suspended in $200 \mu \mathrm{l}$ of BHI were triturated in disposable tubes with matching pellet pestles (Kontes, Vineland, N.J.). The triturated samples were then treated with $10 \mu \mathrm{l}$ of proteinase $\mathrm{K}(120 \mu \mathrm{g} / \mathrm{ml})$, incubated for $1 \mathrm{~h}$ at $37^{\circ} \mathrm{C}$, and heated to $95^{\circ} \mathrm{C}$ for $10 \min$ to inactivate the proteinase $\mathrm{K}$. A 5 - $\mu$ l portion of each suspension was then used in the PCR assay. The assays were performed with a GeneAmp PCR reagent kit in $0.5-\mathrm{ml}$ reaction tubes as recommended by the manufacturer (Perkin-Elmer $\mathrm{Ce}$ tus, Norwalk, Conn.). Each PCR mixture contained DNA template $(5 \mu \mathrm{l})$, two primers suspended at a concentration of $30 \mathrm{pmol} / \mu \mathrm{l}\left(0.5 \mu \mathrm{l}\right.$ of each), $\mathrm{dH}_{2} \mathrm{O}$ $(34.75 \mu \mathrm{l})$, PCR kit $10 \times$ reaction buffer $(5 \mu \mathrm{l})$, four deoxynucleoside triphosphates at a concentration of $200 \mu \mathrm{M}(1 \mu \mathrm{l}$ of each), $1.25 \mathrm{U}$ of Taq polymerase $(0.25 \mu \mathrm{l})$, and an overlay of mineral oil $(25 \mu \mathrm{l})$. Rickettsial strains (Table 1) and rickettsia-free tick tissues were included in PCR assays as positive and negative controls. With both the rickettsial CS gene and rOmpA gene primer sets, each PCR sample was amplified for 35 cycles with a thermocycler (Perkin-Elme Cetus) by using a temperature profile of $95^{\circ} \mathrm{C}$ for $1 \mathrm{~min}, 48^{\circ} \mathrm{C}$ for $30 \mathrm{~s}$, and $60^{\circ} \mathrm{C}$ for 2 min. With the eubacterial 16S rDNA gene primer set, each PCR sample wa amplified for 35 cycles by using a temperature profile of $95^{\circ} \mathrm{C}$ for $1 \mathrm{~min}, 55^{\circ} \mathrm{C}$ for $1 \mathrm{~min}$, and $72^{\circ} \mathrm{C}$ for $2 \mathrm{~min}$.

Sequencing of PCR products. PCR amplification products were purified by using MicroSpin S-400 HR columns (Pharmacia Biotech, Inc., Piscataway, N.J.) prior to sequencing. Both strands of the PCR amplification products generated with the 16S rDNA gene and rOmpA gene forward and reverse primers employed in the PCR assays were sequenced with Sequenase, version 2.0 (United States Biochemical Corp., Cleveland, Ohio). The sequencing primers were designed based on prior sequence determinations. All but one of the gene sequences were generated directly from PCR amplification products. One partial 16S rDNA sequence for Skalkaho ${ }^{\mathrm{T}}$ was determined from a tick collected in 1994 (SK-594). A second partial 16S rDNA sequence for the new rickettsia was generated from a PCR product amplified from an infected tick collected in 1995 (SK-295) and cloned into a pCR2000 plasmid DNA vector (TA cloning kit Invitrogen, San Diego, Calif.). Cultured clones were harvested and purified by cesium chloride equilibrium density gradient centrifugation (42). Four partial rOmpA gene sequences were determined for Skalkaho ${ }^{\mathrm{T}}$ infecting individual ticks collected in 1992 (KG-392), 1994 (SK-594), and 1995 (SK-295), as well as a laboratory colony tick (RML-795). For comparison, partial rOmpA gene sequences were determined for $R$. montana $\mathrm{M} / 5-6$ and $R$. rickettsii HLP (these sequences were not available from GenBank). Appropriate oligodeoxynucleotide primers were purchased commercially (Genemed Bio, San Francisco, Calif.) and were designed based on prior sequence determinations. Gene sequences were aligned and levels of similarity were calculated with the Clustal V program (17). The aligned sequences correspond to positions 29 through 1185 and 91 through 602 on the forward sense strand of the $R$. rickettsii $\mathrm{R}$ 16S rDNA and rOmpA genes, respectively. The GenBank nucleotide sequence accession numbers for the partial 16S rDNA and rOmpA gene sequences of SFG rickettsial strains used to characterize Skalkaho ${ }^{\mathrm{T}}$ are listed in Table 1.

Restriction enzyme analysis of PCR amplification products. DNA digestion and staining of gels were carried out as described previously (14), with minor modifications. DNA amplification products generated from a PCR assay of infected cells from laboratory ticks (RML-795), field-collected ticks (SK-594 and SK-295), and rickettsial strains (Table 1) were analyzed. A 10- $\mu$ l portion of each PCR mixture was digested overnight at $37^{\circ} \mathrm{C}$ with $1 \mu \mathrm{l}$ of restriction enzyme Pst $\mathrm{I}$, RsaI, or AluI (10 U) and $2 \mu$ l of the appropriate $10 \times$ enzyme buffer (New England Biolabs, Beverly, Mass.). The digested PCR products were mixed with $5 \mu \mathrm{l}$ of Ficoll buffer $(0.25 \%$ Orange G, $60 \mathrm{mM}$ EDTA, $10 \mathrm{mM}$ Tris, and $15 \%$ Ficoll 400 in $\mathrm{dH}_{2} \mathrm{O}$ ) and loaded onto $8 \%$ polyacrylamide gels (thickness, $1.5 \mathrm{~mm}$ ) for electrophoretic analysis (42). phiX174 replicative-form DNA cleaved with HaelII was used as a molecular size marker.

\section{RESULTS}

Massive infections of Skalkaho ${ }^{\mathrm{T}}$ were observed only in $D$. andersoni ovarial tissues. Of 115 field-collected ticks, 76 were infected (minimal field infection rate, 66.1\%), with ovarial tissues testing positive for rickettsiae by Giménez staining, an IFA test in which a polyclonal antibody to $R$. rickettsii was used, and PCR assays in which two separate rickettsial gene primer sets were used (Table 2). Identical tests performed with laboratory colony ticks revealed that 33 of 45 female offspring (minimal transovarial transmission rate, $73.3 \%$ ) from the same parent were infected through the adult stage (Table 2). Transstadial transmission was also observed as Skalkaho ${ }^{\mathrm{T}}$ has been maintained in laboratory ticks for two generations.

No rickettsiae were detected by the PCR assays in adult female tick hemocytes, salivary glands, midguts, Malpighian tubules, or hypodermal tissues (Table 2). However, individual, nonintracellular, and very rare rickettsia-like organisms were observed associated with a few female tick midgut tissues and Malpighian tubules following nonspecific Giménez and IFA staining (Table 2). A PCR assay performed with the rickettsial CS gene and rOmpA gene primer sets failed to amplify any products from these samples, suggesting that they were not infected with SFG rickettsiae. The identity of the organisms found remains uncertain. The hemolymph, salivary glands, testicular tissues, Malpighian tubules, midguts, and hypodermal tissues of field-collected and laboratory colony adult male ticks were also apparently free of rickettsial infection (Table 2). In contrast, in both males and females the same tick tissues are susceptible to infection with $R$. rickettsii and other SFG rickettsiae $(14,16,29)$.

The infection rates in tissues stained by the Giménez method were identical to those determined by IFA tests in which a polyclonal antibody to $R$. rickettsii was used. In PCR assays performed with the rickettsial CS gene and rOmpA gene primer sets and these samples we detected rickettsiae in all of the tissues that were positive as determined by staining and IFA tests, and amplification products of the appropriate sizes were generated by both primer sets. An additional five samples that were negative as determined by staining and IFA 
TABLE 3. Reactivity of $R$. peacockii Skalkaho $^{\mathrm{T}}$ and related rickettsiae with MAbs to rOmpA and rOmpB

\begin{tabular}{lccc}
\hline \multirow{2}{*}{ Strain } & \multicolumn{3}{c}{ Reactivity with: } \\
\cline { 2 - 4 } & rOmpB & rOmpA & rOmpA \\
& MAb 13-2 & MAb 14-13 & MAb 13-5 \\
\hline$R$. peacockii Skalkaho ${ }^{\mathrm{T} a}$ & $+^{b}$ & - & - \\
$R$. rickettsii $\mathrm{R}$ & + & + & + \\
$R$. rickettsii HLP & + & + & + \\
$R$. conorii Malish 7 & + & - & + \\
$R$. montana M/5-6 & + & + & + \\
$R$. rhipicephali $85 \mathrm{TW}$ & - & + & + \\
WB8-2 & + & + & + \\
\hline
\end{tabular}

${ }^{a}$ Infected ovarial tissues from laboratory colony ticks (RML-295 and RML795) and field-collected ticks (SK-594 and SK-295) were tested and elicited identical reactivities.

${ }^{b}+$, positive; - , negative.

tests gave PCR amplification products whose RFLP profiles were consistent with those of Skalkaho ${ }^{\mathrm{T}}$.

The reactivities of Skalkaho ${ }^{\mathrm{T}}$ and several other SFG rickettsial strains to MAbs are summarized in Table 3. Both heatsensitive MAb 14-13 and heat-resistant MAb 13-5 to rOmpA failed to bind to Skalkaho ${ }^{\mathrm{T}}$, while at least one of the two MAbs bound strongly to all other rickettsial strains tested (Table 3). Conversely, MAb 13-2 to rOmpB bound strongly to Skalkaho ${ }^{\mathrm{T}}$

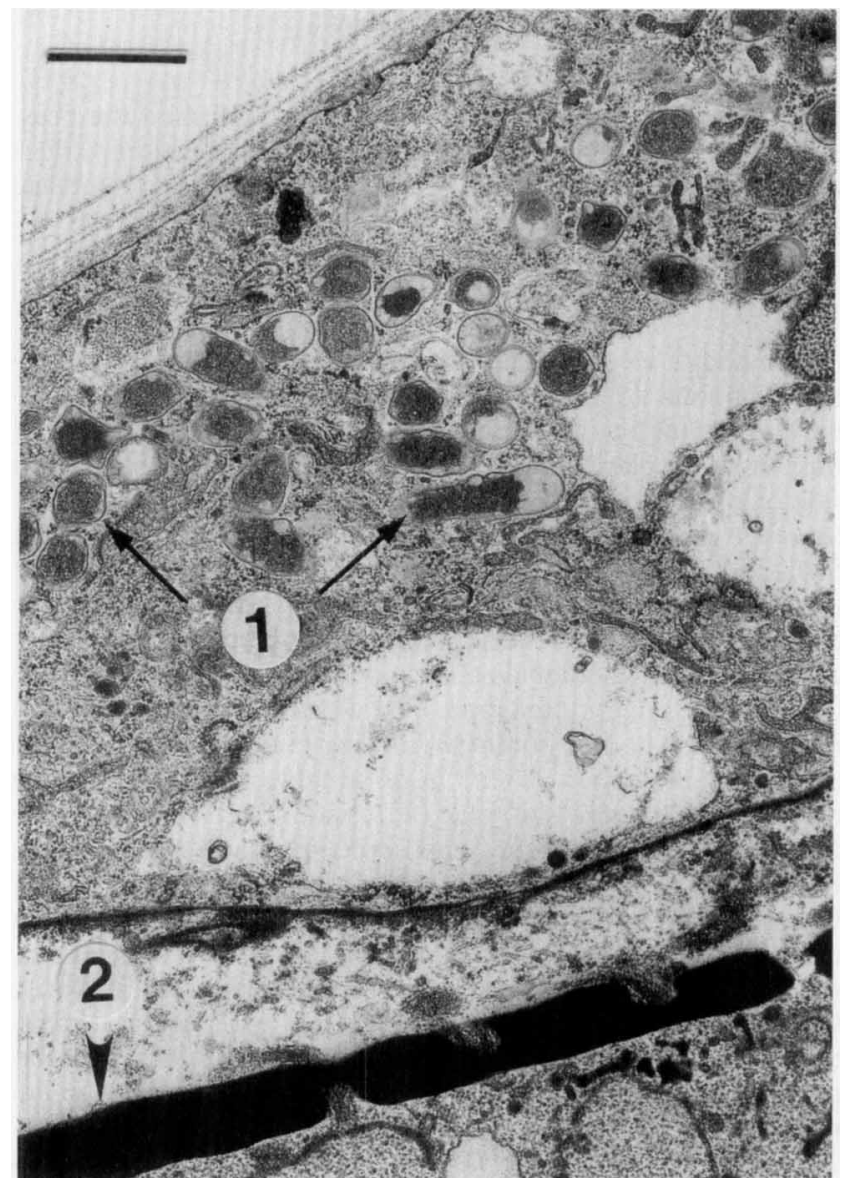

FIG. 1. Transmission electron micrograph of $R$. peacockii Skalkaho ${ }^{\mathrm{T}}$ (arrows 1 ) in a $D$. andersoni ovarial cell beside a developing tick egg (arrowhead 2). Magnification, $\times 39,000$. Bar $=1 \mu \mathrm{m}$
TABLE 4. Levels of $16 \mathrm{~S}$ rDNA gene sequence similarity for R. peacockii Skalkaho $^{\mathrm{T}}$ and several SFG rickettsiae ${ }^{a}$

\begin{tabular}{|c|c|c|c|c|c|c|c|}
\hline \multirow[b]{2}{*}{ Strain } & \multicolumn{7}{|c|}{$\%$ 16S rDNA sequence similarity } \\
\hline & 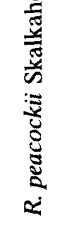 & 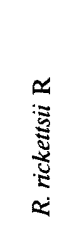 & 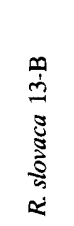 & 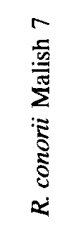 & 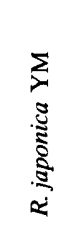 & 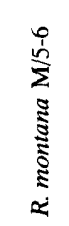 & 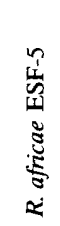 \\
\hline R. peacockii Skalkaho ${ }^{\mathrm{Tb}}$ & 100 & 99.7 & 99.7 & 99.6 & 99.4 & 99.1 & \\
\hline R. rickettsii $\mathrm{R}$ & & 100 & 99.7 & 99.7 & 99.6 & 99.1 & 99.0 \\
\hline R. slovaca $13-\mathrm{B}$ & & & 100 & 99.7 & 99.7 & 99.4 & 99.2 \\
\hline$R$ conorii Malish 7 & & & & 100 & 99.6 & 99.3 & 99.3 \\
\hline R. japonica YM & & & & & 100 & 99.2 & 99.0 \\
\hline R. montana $\mathrm{M} / 5-6$ & & & & & & 100 & 99.0 \\
\hline R. africae ESF-5 & & & & & & & 100 \\
\hline
\end{tabular}

${ }^{a}$ The sequences compared correspond to positions 29 through 1185 on the forward strand of the $R$. rickettsii $\mathrm{R}$ 16S rDNA gene.

${ }^{b}$ The two partial 16S rDNA sequences determined for $R$ peacockii, a sequence amplified from a tick (SK-594) collected in 1994 and a cloned sequence from a tick collected in 1995 (SK-295), were identical.

and all other strains tested except $R$. rhipicephali 85TW (Table 3).

Attempts to cultivate organisms in mammals and cell cultures failed to establish rickettsial colonies. The organism was rare but detectable by PCR and IFA tests through three passages in MTV cells. No rickettsia-induced plaques were detected in Vero cells with agar overlays. Attempts to establish a primary $D$. andersoni tick ovarial tissue cell line were also unsuccessful.

Transmission electron microscopy of $D$. andersoni ovarial tissue revealed packets of putative Skalkaho ${ }^{\mathrm{T}}$ cells replicating intracellularly (Fig. 1) and within developing eggs. The organism was also abundant in the interstitial spaces of the ovaries and was observed only in those ovarial tissues that were positive for rickettsiae as determined by staining and PCR. These rod-shaped rickettsiae were approximately $1.2 \mu \mathrm{m}$ long and 0.4 $\mu \mathrm{m}$ wide.

The levels of sequence similarity between the new organism and other rickettsiae were comparable to the levels of similarity observed among the SFG relatives of Skalkaho ${ }^{\mathrm{T}}$ (Table 4) $(40,41,43)$. The $16 \mathrm{~S}$ rDNA sequence of Skalkaho ${ }^{\mathrm{T}}$ was most similar (level of similarity, 99.7\%) to the sequences of $R$. rickettsii R (three base differences) and Rickettsia slovaca 13-B (four base differences) (Table 4). For comparison, R. rickettsii $\mathrm{R}$ also exhibits $99.7 \%$ similarity to Rickettsia conorii Malish 7 (Table 4). The partial 16S rDNA sequence of Skalkaho ${ }^{T}$ generated from a PCR fragment amplified from a tick collected in 1994 was identical to the sequence of a cloned PCR product amplified from a tick collected in 1995. For the aligned sequences, the base signatures for Skalkaho ${ }^{\mathrm{T}}$ were $\mathrm{T}$ and $\mathrm{C}$ at positions 474 and 532, respectively, on the forward strand of the $16 \mathrm{~S}$ rDNA gene sequence. Furthermore, the four partial rOmpA gene sequences generated for the bacterium from three separate ticks collected in 1992, 1992, and 1995, as well as a laboratory colony tick, were identical. The rOmpA gene sequence of Skalkaho ${ }^{\mathrm{T}}$ was most similar $(93.0 \%)$ to the sequence of $R$. slovaca 13-B (Table 5). A lower level of similarity $(91.6 \%)$ was observed with $R$. rickettsii HLP and R strains (Table 5). For comparison, the rOmpA gene sequence of $R$. slovaca 13-B exhibits $93.0 \%$ similarity to the Rickettsia japonica YM sequence, while the $R$. rickettsii $\mathrm{R}$ sequence exhibits 93.2 
TABLE 5. Levels of rOmpA gene sequence similarity for $R$. peacockii Skalkaho $^{\mathrm{T}}$ and several SFG rickettsiae ${ }^{a}$

\begin{tabular}{|c|c|c|c|c|c|c|c|c|c|c|c|c|c|c|c|c|}
\hline \multirow[b]{2}{*}{ Strain } & \multicolumn{16}{|c|}{$\%$ rOmpA sequence similarity } \\
\hline & 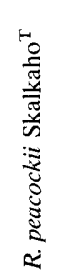 & 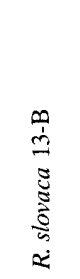 & 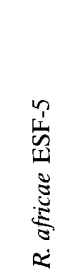 & $\begin{array}{l}n \\
\text { 窇 } \\
\text { n }\end{array}$ & 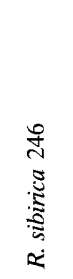 & 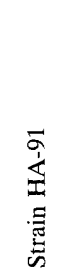 & 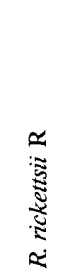 & 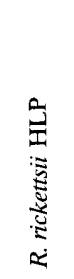 & 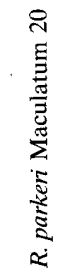 & 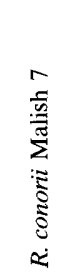 & 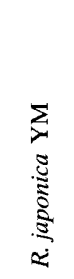 & 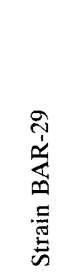 & 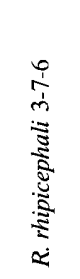 & 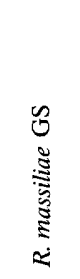 & 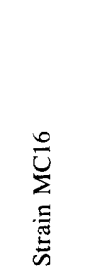 & 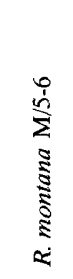 \\
\hline R. peacockii Skalkaho ${ }^{\mathrm{T} b}$ & 100 & 93.0 & 92.6 & 92.4 & 92.0 & 92.0 & 91.6 & 91.6 & 91.2 & 89.8 & 87.9 & 87.7 & 87.5 & 87.3 & 87.3 & 85.5 \\
\hline R. slovaca $13-\mathrm{B}$ & & 100 & 98.6 & 98.4 & 98.0 & 98.2 & 97.1 & 96.7 & 97.3 & 93.9 & 93.0 & 92.8 & 92.6 & 92.6 & 92.2 & 89.8 \\
\hline R. africae ESF-5 & & & 100 & 99.4 & 98.6 & 98.8 & 96.7 & 96.7 & 98.0 & 93.6 & 93.2 & 92.8 & 92.6 & 92.6 & 92.6 & 89.4 \\
\hline $\mathrm{S}$ & & & & 100 & 99.2 & 99.0 & 96.9 & 96.8 & 97.9 & 93.9 & 93.4 & 93.2 & 93.0 & 93.0 & 92.8 & 89.8 \\
\hline R. sibirica 246 & & & & & 100 & 99.0 & 96.5 & 96.5 & 97.3 & 93.6 & 92.8 & 92.6 & 92.4 & 92.4 & 92.2 & 89.2 \\
\hline HA-91 & & & & & & 100 & 96.7 & 96.7 & 97.9 & 93.8 & 92.8 & 93.0 & 92.8 & 92.8 & 92.6 & 90.0 \\
\hline R. rickettsii $\mathrm{R}$ & & & & & & & 100 & 99.6 & 95.3 & 93.2 & 92.6 & 91.6 & 91.4 & 91.4 & 90.8 & 88.4 \\
\hline R. rickettsii HLP & & & & & & & & 100 & 95.3 & 92.8 & 93.0 & 92.0 & 91.8 & 91.8 & 91.2 & 88.6 \\
\hline R. parkeri Maculatum 20 & & & & & & & & & 100 & 92.4 & 91.4 & 91.6 & 91.4 & 91.4 & 91.4 & 88.0 \\
\hline R. conorii Malish 7 & & & & & & & & & & 100 & 90.4 & 89.6 & 89.5 & 89.6 & 88.6 & 86.6 \\
\hline R. japonica YM & & & & & & & & & & & 100 & 92.8 & 91.0 & 90.0 & 90.0 & 88.6 \\
\hline BAR-29 & & & & & & & & & & & & 100 & 99.0 & 99.4 & 97.5 & 89.6 \\
\hline R. rhipicephali 3-7-6 & & & & & & & & & & & & & 100 & 98.8 & 97.5 & 91.4 \\
\hline R. massiliae GS & & & & & & & & & & & & & & 100 & 97.3 & 91.0 \\
\hline MC16 & & & & & & & & & & & & & & & 100 & 91.0 \\
\hline R. montana $\mathrm{M} / 5-6$ & & & & & & & & & & & & & & & & 100 \\
\hline
\end{tabular}

${ }^{a}$ The sequences compared correspond to positions 91 through 602 on the forward strand of the $R$. rickettsii $\mathrm{R}$ rOmpA gene.

${ }^{b}$ Four partial rOmpA gene sequences generated for $R$. peacockii from ticks collected in three separate years (KG-392, SK-594, SK-295) and a laboratory colony tick (RML-795) were identical.

and $92.6 \%$ similarity to the $R$. conorii Malish 7 and $R$. japonica YM sequences, respectively (Table 5).

The partial sequence of the rOmpA gene of Skalkaho ${ }^{\mathrm{T}}$ indicated that there was a deletion of a single base at either position 403 or position 404 on the forward sense strand. This deletion prematurely ends the open reading frame which begins at position 70 in the gene by converting what would be read as CCC-GTA encoding two amino acids (Pro, Val) in $R$. rickettsii to CCT-TAG encoding a single amino acid (Pro) and a translational stop codon in Skalkaho ${ }^{T}$. The deletion occurs in all rOmpA gene sequences obtained for the organism.

RFLP analyses of the PCR products amplified from rickettsiae infecting 35 separate tick ovarial tissues, including tissues from both laboratory (RML-795) and field-collected (KG-392, SK-594, SK-295) ticks, resulted in restriction fragment profiles identical to each other but distinct from the profiles of other known SFG rickettsiae (Fig. 2). No dual infections were detected. Two distantly related rickettsial species occurring in the western United States, $R$. bellii and Rickettsia canada, do not produce an amplification product with the rOmpA gene primer set (14). The PCR product amplified from Skalkaho ${ }^{\mathrm{T}}$ by the rOmpA gene primer set was not cut with RsaI (Fig. 2). All other SFG rickettsiae tested to date except $R$. japonica YM have at least one RsaI digestion site on the DNA products amplified by the rOmpA gene primer set (Fig. 2) $(10,14,41)$. Digestion of the same uncut fragment of Skalkaho ${ }^{\mathrm{T}}$ with Pst $\mathrm{I}$ gave bands at approximately 120,160 , and $250 \mathrm{bp}$, a profile distinct from the profiles of $R$. rickettsii $\mathrm{R}$ (Fig. 2) and other SFG rickettsiae $(14,41)$. This is in agreement with sequence data for Skalkaho ${ }^{T}$ which predicted that $R s a$ I would not cut the fragment due to lack of an appropriate digestion site while Pst I would cut at positions 119 and 278 on the forward strand to produce three fragments that are 118, 159, and 255 bp long. AluI enzyme digests (data not shown) of PCR products ampli- fied by the rickettsial CS gene primer set confirmed the presence of rickettsiae in 35 tick ovaries, and the digestion profiles were indistinguishable from those of other SFG rickettsiae (14).

\section{DISCUSSION}

The ability to detect and differentiate Skalkaho ${ }^{T}$ by molecular techniques provides a promising approach for investigating the cycling, behavior, and interaction of rickettsiae in nature. In particular, the low incidence of RMSF on the eastern side of Bitterroot Valley has never been adequately explained; however, given its abundance there, it seems plausible that Skalkaho $^{T}$ may be responsible for this phenomenon (8). In ongoing studies addressing this hypothesis, workers are trying to determine the incidence of Skalkaho ${ }^{\mathrm{T}}$ on the western side of the valley and whether massive infections of this rickettsia in tick ovarial tissue inhibit transovarial transmission of virulent $R$. rickettsii. Another potential limiting factor of $R$. rickettsii is that the mammalian reservoir of suitable RMSF-amplifying hosts on the eastern side may be resistant to rickettsial infection due to prior exposure and seroconversion to Skalkaho ${ }^{\mathrm{T}}$. Interference via cross-protection has been demonstrated for low- and high-virulence strains of $R$. rickettsii $(35,36)$ and for distantly related SFG rickettsiae $(11,13)$, but no interference was observed for Skalkaho ${ }^{T}$ since guinea pigs inoculated with triturates of wood ticks harboring the ES agent remained susceptible to infection with $R$. rickettsii $(8,29)$. Studies to determine the capacity of the organism to be transmitted to mammals during tick feeding were inconclusive (8).

Considering the high level and stable maintenance of Skalkaho $^{\mathrm{T}}$ in ticks, this bacterium may be beneficial to ovarial cells or may bias ticks toward infection, as has been demonstrated with some arthropod endosymbionts, such as the $\mathrm{AB}$ agent, a 


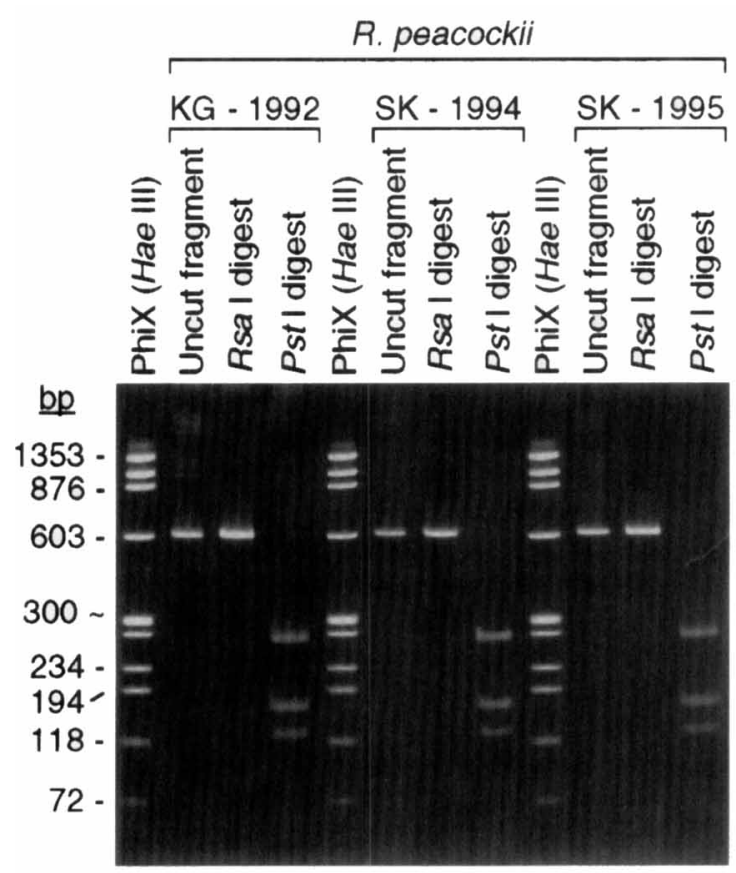

A

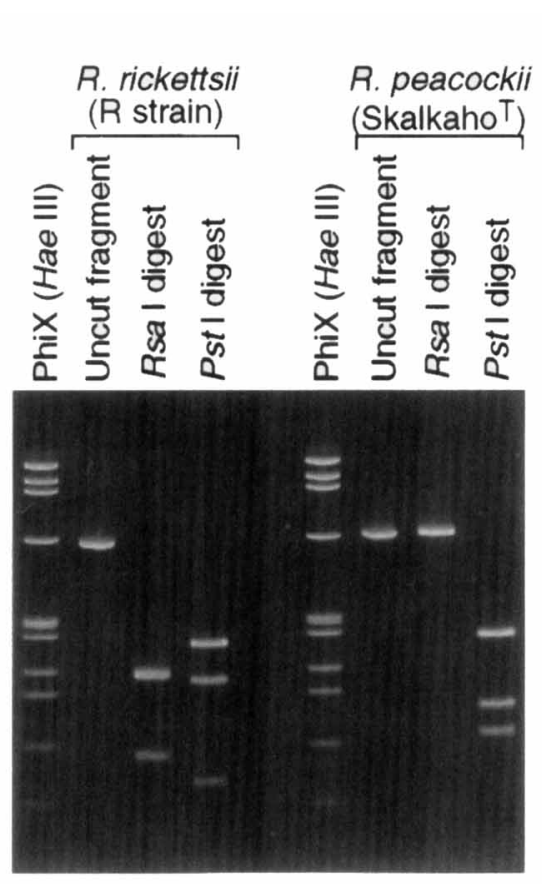

B
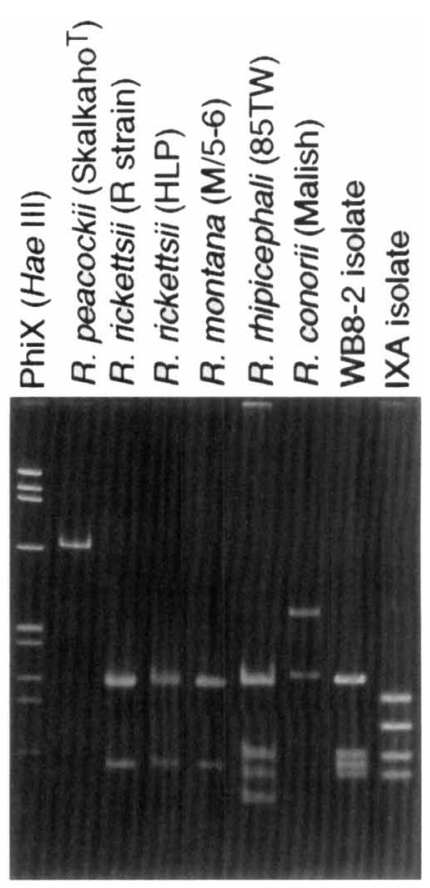

C

FIG. 2. RFLP analysis of PCR products amplified by the rickettsial 190-kDa surface antigen gene primer set. (A) RsaI and PstI enzyme digests of $R$. peacockii strains from ticks collected in 1992, 1994, and 1995. (B) RsaI and PstI enzyme digests of $R$. rickettsii R and $R$. peacockii Skalkaho ${ }^{\mathrm{T}}$. (C) RsaI enzyme digests of SFG rickettsiae. The positions of molecular size standards are indicated on the left.

rickettsial species associated with male killing in the ladybird beetle (48), and other members of the Rickettsiaceae $(26,45)$. If this is true, the result would be selection for a greater percentage of $D$. andersoni tick ovarial cells infected with Skal$\mathrm{kaho}^{\mathrm{T}}$. The biological properties which the organism may share with other rickettsia-like endosymbionts $(44,48)$ remain to be determined.

Description of Rickettsia peacockii sp. nov. We propose the name Rickettsia peacockii (pea.cock'i.i. M.L. gen. n. peacockii of Peacock, named after rickettsiologist M. G. Peacock) for a new SFG rickettsial species which maintains natural infections in wood ticks via transstadial and transovarial transmission. Although $R$. peacockii could not be maintained in laboratory tissue culture, there is precedent for naming and describing uncultivable prokaryotes $(1,22)$. A type strain (Skalkaho) was characterized directly from an infected $D$. andersoni tick (SK594) which was used to generate $16 \mathrm{~S}$ rDNA and rOmpA gene sequences (Tables 4 and 5), RFLP profiles (Fig. 2), and IFA reactivity data (Table 3 ) and to establish an infected laboratory tick colony (RML-795).

The localization of $R$. peacockii Skalkaho ${ }^{\mathrm{T}}$ in tick ovarial tissue, our inability to maintain infections in mammalian systems, the apparent lack or truncation of the rOmpA surface antigen, and the gene sequence data indicate that this fastidious microorganism is a unique rickettsial species. With its stable maintenance in ticks, $R$. peacockii Skalkaho ${ }^{\mathrm{T}}$ appears to be an endosymbiont whose biology contrasts with the biology of other rickettsiae. Continued studies on the organism should contribute to our understanding of rickettsia-vector-mammalian host dynamics and the mechanisms which virulent rickettsiae employ to infect and ultimately damage host cells.

\section{ACKNOWLEDGMENTS}

We express our gratitude to Robert Karstens for his assistance in tick collection, to Paul Policastro for providing tick cell cultures, to Dave Dorward for aiding in electron microscopy, and to Ted Hackstadt for supplying MAbs. Gary Hettrick and Bob Evans deserve special thanks for preparing the figures.

\section{REFERENCES}

1. Aksoy, S. 1995. Wigglesworthia gen. nov. and Wigglesworthia glossinidia sp. nov., taxa consisting of the mycetocyte-associated, primary endosymbionts of tsetse flies. Int. J. Syst. Bacteriol. 45:848-851.

2. Anacker, R. L., R. E. Mann, and C. Gonzales. 1987. Reactivity of monoclonal antibodies to Rickettsia rickettsii with spotted fever group and typhus group rickettsiae. J. Clin. Microbiol, 25:167-171.

3. Azad, A. F., J. B. Sacci, W. M. Nelson, G. A. Dasch, E. T. Schmidtmann, and M. Carl. 1992. Genetic characterization and transovarial transmission of a typhus-like rickettsia found in cat fleas. Proc. Natl. Acad. Sci. USA 89:43-46.

4. Bell, E. J., G. M. Kohls, H. G. Stoenner, and D. B. Lackman. 1963. Nonpathogenic rickettsiae related to the spotted fever group isolated from ticks, Dermacentor variabilis and Dermacentor andersoni, from eastern Montana J. Immunol. 90:770-781.

5. Bozeman, F. M., A. Shirai, J. W. Humphries, and H. S. Fuller. 1967. Ecology of Rocky Mountain spotted fever. II. Natural infection of wild mammals and birds in Virginia and Maryland. Am. J. Trop. Med. Hyg. 16:48-59.

6. Burgdorfer, W. 1970 . Hemolymph test. A technique for detection of rickettsiae in ticks. Am. J. Trop. Med. Hyg. 19:1010-1014.

7. Burgdorfer, W. 1975. A review of Rocky Mountain spotted fever (tick-borne typhus), its agent, and its tick vectors in the United States. J. Med. Entomol. 12:269-278.

8. Burgdorfer, W., S. F. Hayes, and A. J. Mavros. 1981. Non-pathogenic rickettsiae in Dermacentor andersoni: a limiting factor for the distribution of Rickettsia rickettsii, p. 585-594. In W. Burgdorfer and R. L. Anacker (ed.), Rickettsiae and rickettsial diseases. Academic Press, New York, N.Y.

9. Dalton, M. J., M. J. Clarke, R. C. Holman, J. W. Krebs, D. B. Fishbein, J. G. Olson, and J. E. Childs. 1995. National surveillance for Rocky Mountain spotted fever, 1981-1992: epidemiological risk factors for fatal outcome. Am. J. Trop. Med. Hyg. 52:405-413.

10. Eremeeva, M., Y. Xuejie, and D. Raoult. 1994. Differentiation among spotted fever group rickettsiae species by analysis of restriction fragment length 
polymorphism of PCR-amplified DNA. J. Clin. Microbiol 32:803-810.

11. Feng, W. C., and J. L. Werner. 1980. Serological cross-reaction and crossprotection in guinea pigs infected with Rickettsia rickettsii and Rickettsia montana. Infect. Immun. 28:627-629.

12. Gage, K. L., R. D. Gilmore, R. K. Karstens, and T. G. Schwan. 1992 Detection of Rickettsia rickettsii in saliva, hemolymph and triturated tissues of infected Dermacentor andersoni ticks by polymerase chain reaction. Mol. Cell. Probes 6:333-341.

13. Gage, K. L., and T. R. Jerrells. 1992. Demonstration and partial characterization of antigens of Rickettsia rhipicephali that induce cross-reactive cellular and humoral immune responses to Rickettsia rickettsii. Infect. Immun. 60:5099-5106.

14. Gage, K. L., M. E. Schrumpf, R. K. Karstens, W. Burgdorfer, and T. G. Schwan. 1994. DNA typing of rickettsiae in naturally infected ticks using a polymerase chain reaction/restriction fragment length polymorphism system. Am. J. Trop. Med. Hyg. 50:247-260.

15. Giménez, D. F. 1964. Staining rickettsiae in yolk-sac cultures. Stain Technol. 39:135-140.

16. Hayes, S. F., and W. Burgdorfer. 1989. Interactions between rickettsial endocytobionts and their tick hosts, p. 235-251. In W. Schwemmler and G. Gassner (ed.), Insect endocytobiosis: morphology, physiology, genetics, and evolution. CRC Press, Inc., Boca Raton, Fla.

17. Higgins, H., A. J. Bleasby, and R. Fuchs. 1992. CLUSTAL V: improved software for multiple sequence alignment. CABIOS 8:189-191.

18. Jellison, W. L., and C. B. Philip. 1933. Technique for routine and experimental feeding of certain ixodid ticks on guinea pigs and rabbits. Public Health Rep. 48:1081-1082.

19. Kelly, P. J., D. Raoult, and P. R. Mason. 1991. Isolation of spotted fever group rickettsias from triturated ticks using a modification of the centrifugation-shell vial technique. Trans. R. Soc. Trop. Med. Hyg. 85:397-398.

20. Kelly, P. J., L. Beati, P. R. Mason, L. A. Mathewman, V. Roux, and D. Raoult. 1996. Rickettsia africae sp. nov., the etiological agent of African tick bite fever. Int. J. Syst. Bacteriol. 46:611-614.

21. Kohls, G. M. 1937. Tick rearing methods with special reference to the Rocky Mountain wood tick, Dermacentor andersoni, p. 3-13. In Culture methods for invertebrate animals. Comstock Publishing Co., Ithaca, N.Y.

22. Lapage, S. P., P. H. A. Sneath, E. F. Lessel, V. B. D. Skerman, H. P. R. Seeliger, and W. A. Clarke (ed.). 1992. International code of nomenclature of bacteria. 1990 revision. American Society for Microbiology, Washington, D.C.

23. Marchette, N. 1982. Ecological relationships and evolution of the rickettsiae CRC Press, Inc., Boca Raton, Fla.

24. McDonald, K. 1984. Osmium ferricyanide fixation improves microfilament preservation and membrane visualization in a variety of animal cell types. $\mathrm{J}$. Ultrastruct. Res. 86:107-118.

25. Munderloh, U. G., and T. K. Kurtti. 1989. Formulation of medium for tick cell culture. Exp. App. Acarol. 7:219-229.

26. Nogge, G. 1981. Significance of symbionts for the maintenance of an optimal nutritional state for successful reproduction in hematophagous arthropods. Parasitology 82:299-304.

27. O'Neill, S. L., R. Giordano, A. M. E. Colbert, T. L. Karr, and H. M. Robertson. 1992. 16S rRNA phylogenetic analysis of the bacterial endosymbionts associated with cytoplasmic incompatibility in insects. Proc. Natl. Acad. Sci. USA 89:2699-2702.

28. Ormsbee, R., M. Peacock, R. Gerloff, G. Tallent, and D. Wike. 1978. Limits of rickettsial infectivity. Infect. Immun. 19:239-245.

29. Parker, R. R., and R. R. Spencer. 1926. Rocky Mountain spotted fever: a study of the relationship between the presence of rickettsia-like organisms in tick smears and infectiveness of the same ticks. Public Health Rep. 41:461469.
30. Parker, R. R., E. G. Pickens, D. B. Lackman, E. J. Bell, and F. B. Thraikill, 1951. Isolation and characterization of Rocky Mountain spotted fever from the rabbit tick Haemaphysalis leporis-palustris Packard. Public Health Rep. 66:455-463

31. Peacock, M. G., W. Burgdorfer, and R. A. Ormsbee. 1971. Rapid fluorescentantibody conjugation procedure. Infect. Immun. 3:355-357.

32. Philip, C. B. 1959. Some epidemiological considerations in Rocky Mountain spotted fever. Public Health Rep. 74:595-600.

33. Philip, R. N., and E. A. Casper. 1981. Serotypes of spotted fever group rickettsiae isolated from Dermacentor andersoni (Stiles) ticks in western Montana. Am. J. Trop. Med. Hyg. 30:230-238.

34. Price, E. G. 1948. Fighting spotted fever in the Rockies. Naegele Printing Co., Helena, Mont.

35. Price, W. H. 1953. Interference phenomenon in animal infections with rickettsiae of Rocky Mountain spotted fever. Proc. Soc. Exp. Biol. Med. 82:180184.

36. Price, W. H. 1953. The epidemiology of Rocky Mountain spotted fever. I. The characterization of strain virulence of Rickettsia rickettsii. Am. J. Hyg. 58:248-268.

37. Radulovic, S., J. A. Higgins, D. C. Jaworski, G. A. Dasch, and A. F. Azad. 1995. Isolation, cultivation, and partial characterization of the ELB agent associated with cat fleas. Infect. Immun. 63:4826-4829.

38. Regnery, R. L., C. L. Spruill, and B. D. Plikaytis. 1991. Genotypic identification of rickettsiae and estimation of intraspecies sequence divergence for portions of two rickettsial genes. J. Bacteriol. 173:1576-1589.

39. Ricketts, H. T. 1909. Some aspects of Rocky Mountain spotted fever as shown by recent investigations. Med. Rec. 76:843-855.

40. Roux, V., and D. Raoult. 1995. Phylogenetic analysis of the genus Rickettsia by 16 S rDNA sequencing. Res. Microbiol. 146:385-396.

41. Roux, V., P.-E. Fournier, and D. Raoult. 1996. Differentiation of spotted fever group rickettsiae by sequencing and analysis of restriction fragmen length polymorphism of PCR-amplified DNA of the gene encoding the protein rOmpA. J. Clin. Microbiol. 34:2058-2065.

42. Sambrook, J., E. Fritsch, and T. Maniatis. 1989. Molecular cloning: a laboratory manual, 2nd ed. Cold Spring Harbor Press, Cold Spring Harbor, N.Y.

43. Stothard, D. R., and P. A. Fuerst. 1995. Evolutionary analysis of the spotted fever and typhus groups of Rickettsia using 16S rRNA gene sequences. Syst. Appl. Microbiol. 18:52-61.

44. Sutakova, G., and J. Rehácek. 1991. Symbiotic microorganisms (endocytobionts) in Dermacentor reticulatus ticks, p. 41-43. In F. Dushabek and V. Bukva (ed.), Modern acarology, vol. 2. Academia, Prague, Czech Republic.

45. Wade, M. J., and N. W. Chang. 1995. Increased male fertility in Tribolium confusum beetles after infection with the intracellular parasite Wolbachia. Nature 373:72-74.

46. Weisburg, W. B., M. E. Dobson, J. E. Samuel, G. A. Dasch, L. P. Mallavia O. Baca, L. Mandelco, J. E. Sechrest, E. Weiss, and C. R. Woese. 1989 Phylogenetic diversity of the rickettsiae. J. Bacteriol. 171:4202-4206.

47. Weiss, E., and J. W. Moulder. 1984. Genus I. Rickettsia, p. 688-698. In N. R. Krieg and J. G. Holt (ed.), Bergey's manual of systematic bacteriology, vol. 1. The Williams \& Wilkins Co., Baltimore, Md.

48. Werren, J. H., G. D. D. Hurst, W. Zhang, J. A. J. Breeuwer, R. Stouthamer, and M. E. N. Majerus. 1994. Rickettsial relative associated with male killing in the ladybird beetle (Adalia bipunctata). J. Bacteriol. 176:388-394.

49. Wike, D. A., and W. Burgdorfer. 1972. Plaque formation in tissue culture by Rickettsia rickettsii isolated from whole blood and tick hemolymph. Infect. Immun. 6:736-738.

50. Yunker, C. E. 1987. Preparation and maintenance of arthropod cell cultures Acari, with emphasis on ticks, p. 35-51. In C. E. Yunker (ed.), Arboviruses in arthropod cells in vitro, vol. 1. CRC Press, Inc., Boca Raton, Fla. 